\title{
Actions of BAFF in B cell maturation and its effects on the development of autoimmune disease
}

\section{F Melchers}

BAFF, a member of the family of tumour necrosis factor (TNF) ligands, is essential for the development of peripheral mature, long lived $B$ lymphocytes. It binds to three different receptors, BCMA, TACl, and BAFF-R, which are all members of the family of TNF receptors. Defects in the genes encoding BAFF or BAFF-R abolish the generation of mature $B$ cells. BAFF is made by myeloid cells whereas BAFF-R is expressed preferentially on B cells. BAFF induces polyclonal maturation of resting, short lived immature $B$ cells to resting, long lived mature B cells without proliferation. Lupus erythematodes prone mice have elevated blood levels of BAFF, and treatment of these mice with the BAFF decoy receptor (BCMA-lg) prevents the onset of this systemic autoimmune disease. Human lupus patients also have elevated blood levels of BAFF. Treatment with BAFF neutralising agents (decoy receptors, monoclonal antibodies) should prevent, delay, or, at least, slow down the disease.

$\mathrm{B}$ AFF (also called BLyS, TALL-1, THANK, and ZNF- $4^{1-5}$ ) is a member of the family of tumour necrosis factor (TNF) ligands (for a review see Bodmer et $a l^{6}$ ). It is a type 2 transmembrane protein which can be expressed on the surface of the cells that produce it. It can also be proteolytically processed by the subtilisin-like furin family member proteases $^{17}$ so that it is secreted from the cells as a soluble ligand. Like all other TNF ligands, BAFF assembles as a trimer for action on its receptors.

BAFF is produced by cells of the myeloid cell lineage, ${ }^{14}$ notably by dendritic cells that express CDIlc at high levels. ${ }^{8}$ It is possibly also produced by some T cells. ${ }^{1}$ It is likely that other, as yet unidentified, cells produce BAFF at sites where B cells and plasma cells are induced to, or maintained at, longevity.

The gene encoding BAFF is located on human chromosome $13 \mathrm{q} 34$ and on mouse chromosome $8 .{ }^{149}$ The human $13 \mathrm{q} 34$ locus is often translocated in Burkitt's lymphomas. ${ }^{10}$

Both human and mouse BAFF bind to three receptors with comparable affinities: BCMA, TACI, and BAFF-R. ${ }^{511-17}$ All three receptors are type 1 single transmembrane receptors and belong to the family of TNF receptors. All three are expressed on CD19 B lymphocytes, and TACI is also expressed on some T cells. " $11-131819$ BAFF-R, in its soluble form as a "decoy" receptor-a fusion protein of the extracellular domains of BAFF-R with the Fc portion of IgG-does not bind to 21 other members of the TNF ligand family. Most notable is its inability to bind to APRIL. ${ }^{36}$ APRIL, another member of the TNF-like ligand family, has so far not been detected in normal tissues, but is strongly up regulated in many tumour cells. ${ }^{31320}$ Some tumour cells do not express BAFF-specific receptors but respond to APRIL, suggesting that APRIL also has its specific receptor. ${ }^{19-21}$ APRIL, like BAFF, binds to BCMA and to TACI but not to BAFF-R, whereas BAFF binds to BCMA, TACI, and BAFF-R, but not to APRIL-R.

\section{BAFF AND ITS RECEPTORS IN B CELL DEVELOPMENT} Various strategies have been used to discover the roles of BAFF and its receptors in the in vitro responses and in vivo development of responses of B cells: $(a)$ in vivo administration of soluble ligand BAFF or soluble BAFF decoy receptors; $(b)$ in vitro effects of these soluble ligands and decoy receptors on different $\mathrm{B}$ lineage cell populations at different stages of development responding to different stimuli in transgenic mice overexpressing the ligand BAFF, and in mice in which the genes encoding either the ligands or the receptors have been inactivated by targeted deletion.

\section{EFFECTS OF SOLUBLE LIGAND BAFF ON B LYMPHOCYTES IN VIVO}

BAFF, at doses of $20 \mu \mathrm{g}$ per mouse, enhances responses to Pneumovacs Z3 vaccine, a T cell independent antigen, about 10 -fold. This enhancement could be obtained even 10 days after the vaccination, and IgM as well as IgA titres, but not IgG titres, were increased-in line with the expected Ig class response of a $\mathrm{T}$ cell independent antigen. ${ }^{22}$ Injection of BAFF also enhanced immune responses to $\mathrm{T}$ cell dependent antigens, such as DNP-BSA, here also in IgG titres. Noteworthy is the increase in $\operatorname{IgM}$ titres in experimentally unstimulated mice by BAFF injection, a scenario that may favour the development of autoimmune B cells.

\section{EFFECTS OF SOLUBLE DECOY RECEPTORS}

Human BCMA can bind mouse BAFF. ${ }^{11}$ Hence, BCMA-Ig decoy receptor was injected at $400 \mu \mathrm{g}$ per mouse 4 times, three days apart. A twofold reduction in the total number of B220 B cells in the periphery was observed. The same result was obtained with TACI-Ig decoy receptor. ${ }^{23} \mathrm{~B}$ lineage cells in bone marrow were unaffected, and Bl cells were only marginally affected.

TACI-Ig injection also inhibited collagen induced arthritis, a disease known to depend on autoantibodies for its progression. ${ }^{24}$

\section{TRANSGENIC EXPRESSION OF BAFF IN MICE}

Three different BAFF transgenic mouse strains have been generated that express BAFF under the control of the liver specific $\alpha_{1}$ antitrypsin promoter and the APO-E enhancer, ${ }^{25}$ the $\beta$ actin promoter, ${ }^{26}$ or $\mathrm{V}_{\mathrm{H}}$ promoter/E $\mu$ enhancer. ${ }^{27}$ The phenotypes of these mice are remarkably similar. B lineage cells in bone marrow appear unchanged. In the peripheral, secondary lymphoid organs, type 2 immature and mature B cell numbers are expanded. CD4 and CD8 T cells are only increased twofold, but they, like the peripheral B cells, show an activated phenotype. The follicular, B cell-rich areas in lymph nodes and spleen are expanded, and the numbers and sizes of germinal centres are increased. In particular, B cells in the marginal zone of the spleen are expanded..$^{25}$

The $\mathrm{V}_{\mathrm{H}} / \mathrm{E} \mu$ controlled BAFF transgenic mice have elevated levels of Bla-type cells. These cells have been shown to be involved in autoantibody production with low avidity for a 
number of autoantigens and foreign antigens, hence showing cross reactivity. ${ }^{21}$

All BAFF transgenic mice had measurable quantities of BAFF in their blood. All the mice developed elevated levels of IgM, IgG, IgA, and IgE in their blood, even on nonautoimmune prone genetic backgrounds. In fact, they developed systemic lupus erythematosus, with the classical hallmarks of double stranded DNA specific autoantibodies. Treatment with decoy receptors delayed the onset of the systemic autoimmune disease.

\section{BAFF IN LUPUS PRONE MICE}

$\mathrm{NZB} \times \mathrm{NZW} \mathrm{F}_{1}$ mice, as well as MRL/lpr mice, develop lupus erythematodes spontaneously. With the onset of the disease, elevated levels of BAFF become detectable in the blood. ${ }^{5}$ Injection of soluble decoy receptors for BAFF (BCMA-Ig and TACIIg) delays the onset of the disease. Mice treated with decoy receptors had reduced numbers of peripheral B cells, suggesting that BAFF may maintain longevity in those pathogenically active $B$ cells that propagate the disease.

The effects of BAFF in transgenic and in lupus prone mice indicate that BAFF may act in a polyclonal fashion on B cells.

\section{BAFF DEFICIENT MICE}

Two BAFF deficient mouse strains have been generated by targeted inactivation of the BAFF gene. ${ }^{23}{ }^{27}$ Both strains had indistinguishable phenotypes. Severe loss of B cells was observed in the periphery, whereas B lineage cells in the bone marrow appeared normal in numbers and phenotypes. Depletion of peripheral B cells affected mostly the follicular and marginal zone, whereas B cells directly adjacent to the $\mathrm{T}$ cell rich area (in the periarteriolar sheet of the spleen and paracortical areas of the lymph nodes) remained relatively normal. $\mathrm{T}$ cell numbers and phenotypes were normal. In detail, the defect was localised in B cell development at the transition from immature B cells of type 1 (ClqRp CD21-, $\mathrm{CD}^{2} 3^{-}, \operatorname{sIg}^{\mathrm{hi}}, \operatorname{sIgD}^{\text {lo }}$ ) to immature B cells of type 2 (ClqRp $\left.\mathrm{CD} 21, \mathrm{CD} 23, \operatorname{sIgM}^{\text {inter }}, \operatorname{sIgD}^{\text {hi }}\right)$ - that is, before the mature $\mathrm{B}$ cells (ClqRp- CD21, CD23, sIgM ${ }^{\text {inter }}$, $\operatorname{sIgD}^{\text {hi }}$ ).

Responses to $\mathrm{T}$ cell independent and $\mathrm{T}$ cell dependent antigens were found to be severely reduced.

In contrast with the conventional B cells found normally in follicular regions of secondary lymphoid organs, Bl cells in the gut associated lymphoid tissues, especially in the lamina propria, were found in normal numbers. Hence, whereas IgG levels were greatly reduced in the BAFF deficient mice, IgA levels were almost normal. This suggests that $\mathrm{Bl}$ cell development is independent of BAFF, and that a considerable part of the IgA produced in the gut associated lymphoid system is generated by Bl cells. ${ }^{28} 29$

\section{BAFF RECEPTOR DEFICIENT MICE}

On B cells, BAFF recognises three receptors: BCMA, TACI, and BAFF-R. The first two receptors have been inactivated by targeted deletion, and, for the third, a naturally occurring mutant strain $\left(\mathrm{A} / \mathrm{wysuJ}_{\mathrm{w}}\right)$ has been identified.

BCMA deficient mice are normal in all precursor, immature, and mature compartments and respond normally to $\mathrm{T}$ cell independent and dependent antigens. ${ }^{30}$ As the BAFF- $R$ deficient, $\mathrm{A} /$ wysus $_{\text {mice }}$ are deficient in $\mathrm{B}$ cell maturation (see below), BCMA appears to be not only a redundant but, in fact, an unimportant receptor for this development.

TACI deficient mice ${ }^{30}{ }^{31}$ have normal numbers and phenotypes of B lineage cells in the bone marrow, but show twice the number of circulating and splenic B cells, with expanded follicular and marginal zone areas in the peripheral lymphoid organs. The hyperplasia is restricted to B cells, and is observed primarily in spleen and much less in lymph nodes. Immature $B$ cells type 1 are increased threefold in the spleen, type 2 are increased twofold, and marginal zone B cells are increased fivefold above normal. Serum Ig levels are normal. However, responses to $\mathrm{T}$ cell independent and dependent antigens are stronger. Hence, TACI may render B cells more prone to proliferation without enhancing their capacity to secrete antibodies.

Furthermore, TACI deficient mice were shown to be deficient in response to T cell independent antigens of type 2, suggesting a role for this BAFF receptor in these usually bacterial carbohydrate associated responses.

In summary, TACI may modulate BAFF responses in concert with BAFF-R, possibly by tuning down proliferation and/or maturation of immature B cells.

$\mathrm{A} /$ Wysu $_{\text {w }}$ mice have a deletion of exon 3 of the BAFF-R gene, which encodes the intracellular signalling domain of the receptor. ${ }^{32}$ The genetic defect may be more extensive. ${ }^{33}$ The BAFF-R is still deposited on the surface but is presumably unable to signal. ${ }^{16} \mathrm{~A} /$ wysu $_{\text {wy }}$ mice show a phenotype that closely resembles that of BAFF deficient mice. ${ }^{34-36}$ Whereas conventional type B cells are greatly reduced, Bl type B cells occur in normal numbers and with apparently unaltered reactivities. From these results it appears that the interaction of BAFF with BAFF-R is the only mandatory interaction controlling the maturation of conventional type B cells. TACI may be an inhibitory modulator in this process.

\section{IN VITRO RESPONSES OF B CELLS TO BAFF}

In tissue culture, BAFF induces immature B cells of type 1 and type 2 as well as mature B cells of spleen to increased longevity in vitro. ${ }^{37}$ It does so with all B cells - that is, polyclonallyand without stimulating proliferation of these resting cells. It also induces phenotypic and functional changes so that all immature B cells lose the expression of ClqRp and up regulate IgD, CD21, and CD23. The BAFF treated immature B cells are no longer induced by $\operatorname{IgM}$ specific antibodies to undergo apoptosis but now proliferate in response to this polyclonal stimulus.

\section{HOW COULD BAFF BREAK B CELL TOLERANCE?}

It appears that in BAFF transgenic mice which develop lupus, BAFF induces survival and maturation of immature B cells that might normally be negatively selected - that is, signalled to die by apoptosis. Such a scenario has so far not been observed in the action of BAFF on such immature B cells in vitro. ${ }^{37}$ Therefore we need to understand in much more detail how sIgM, sIgD, BAFF-R, and TACI, as well as other possible costimulatory interactions on B cells in this process of maturation, decide on apoptosis or survival. It is also of prime importance to understand the nature and action of $\mathrm{T}$ cell independent and $\mathrm{T}$ cell dependent, foreign antigen specific or autoantigen/foreign antigen cross reactive antigens in this decision. It is evident that B cells with autoreactivity contribute to autoimmune disease, and that BAFF may be an important target for modulating $\mathrm{B}$ cell performance and its influence on inflammatory processes.

\section{Author's affiliation}

F Melchers, Biozentrum, Department of Cell Biology, University of Basel, Basel, Switzerland

Correspondence to: Dr F Melchers, Biozentrum, Department of Cell Biology, University of Basel, Klingelbergstrasse 50-70, CH-4056 Basel, Switzerland; fritz.melchers@unibas.ch

\section{REFERENCES}

1 Schneider P, MacKay F, Steiner V, Hofmann K, Bodmer JL, Holler N, et al. BAFF, a novel ligand of the tumor necrosis factor family, stimulates $B$ cell growth. J Exp Med 1999: 189:1747-56.

2 Shu HB, Hu WH, Johnson H. TALL-1 is a novel member of the TNF family that is down-regulated by mitogens. J Leukoc Biol 1999;65:680-3

3 Mukhopadhyay A, Ni J, Zhai Y, Yu GL, Aggarwal BB. Identification and characterization of a novel cytokine, THANK, a TNF homologue that activates apoptosis, nuclear factor-kappaB, and c-Jun $\mathrm{NH2}$-terminal kinase. J Biol Chem 1999;274:15978-81. 
4 Moore PA, Belvedere O, Orr A, Pieri K, LaFleur DW, Feng P, et al. BLyS: member of the tumor necrosis factor family and $B$ lymphocyte stimulator. Science 1999;285:260-3

5 Gross JA, Johnston J, Mudri S, Enselman R, Dillon SR, Madden K, et al. $\mathrm{TACl}$ and $\mathrm{BCMA}$ are receptors for a TNF homologue implicated in B-cell autoimmune disease. Nature 2000;404:995-9.

6 Bodmer J-L, Schneider P, Tschopp J. The molecular architecture of the TNF superfamily. Trends in Biochem Sciences 2002;27:10-26.

7 Chen Y, Molloy SS, Thomas L, Gambee J, Bachinger HP, Ferguson B, et al. Mutations within a furin consensus sequence block proteolytic release of ectodysplasin A and cause X-linked hypohidrotic ectoderma dysplasia. Proc Natl Acad Sci USA 2001;98:7218-23.

8 Nardelli B, Belvedere O, Roschke V, Moore PA, Olsen HS, Migone TS et al. Synthesis and release of B-lymphocyte stimulator from myeloid cells. Blood 2001:97:198-204.

9 Jiang $Y$, Ohtsuji M, Abe M, Li N, Xiu Y, Wen S, et al. Polymorphism and chromosomal mapping of the mouse gene for B-cell activating factor belonging to the fumor necrosis factor familly (Baff) and association with the autoimmune phenotype. Immunogenetics 2001;53:810-13.

10 Berger $\mathbf{R}$, Le Coniat $M$, Derre J, Vecchione D. Secondary nonrandom chromosomal abnormalities of band 13q34 in Burkitt

lymphoma-leukemia. Genes Chromosomes Cancer 1989;1:115-18.

11 Thompson JS, Schneider P, Kalled SL, Wang L, Lefevre EA, Cachero TG, et al. BAFF binds to the tumor necrosis factor receptor-like molecule B cell maturation antigen and is important for maintaining the peripheral $B$ cell population. J Exp Med 2000; 192:129-35.

12 Xia XZ, Treanor J, Senaldi G, Khare SD, Boone T, Kelley M, et al. TACI is a TRAF-interacting receptor for TALL-1, a tumor necrosis factor family member involved in B cell regulation. J Exp Med 2000;192:137-43.

13 Marsters SA, Yan M, Pitti RM, Haas PE, Dixit VM, Ashkenazi A Interaction of the TNF homologues BLyS and APRIL with the TNF receptor homologues BCMA and TACI. Curr Biol 2000;10:785-8.

14 Shu HB, Johnson $\mathrm{H}$. B cell maturation protein is a receptor for the tumor necrosis factor family member TALL-1. Proc Natl Acad Sci USA 2000:97:9156-61.

15 Wu Y, Bressette D, Carrell JA, Kaufman T, Feng P, Taylor K, et al. Tumor necrosis factor (TNF) receptor superfamily member $\mathrm{TACl}$ is a high affinity receptor for TNF family members APRIL and BLyS. J Biol Chem 2000;275:35478-85.

16 Thompson JS, Bixler SA, Qian F, Vora K, Scott ML, Cachero TG, et al. BAFF-R, a newly identified TNF receptor that specifically interacts with BAFF. Science $2001 ; 293: 2108-11$

17 Gras MP, Laabi Y, Linares-Cruz G, Blondel MO, Rigaut JP, Brouet JC, et al. BCMAp: an integral membrane protein in the Golgi apparatus of human mature B lymphocytes. Int Immunol 1995;7:1093-106.

18 Laabi Y, Gras MP, Brovet JC, Berger R, Larsen CJ, Tsapis A. The BCMA gene, preferentially expressed during $B$ lymphoid maturation, is bidirectionally transcribed. Nucleic Acids Res 1994;22:1 147-54

19 Rennert P, Schneider P, Cachero TG, Thompson J, Trabach L, Hertig S, et al. A soluble form of B cell maturation antigen, a receptor for the tumor necrosis factor family member APRIL, inhibits tumor cell growth. J Exp Med 2000; 192:1677-84

20 Ware CF. APRIL and BAFF connect autoimmunity and cancer. J Exp Med 2000:192:F35-8.
21 Hahne M, Kataoka T, Schroter M, Hofmann K, Irmler M, Bodmer JL, et al. APRIL, a new ligand of the tumor necrosis factor family, stimulates tumor cell growth. J Exp Med 1998;188:1185-90.

22 Do RK, Hatada E, Lee H, Tourigny MR, Hilbert D, Chen-Kiang S. Attenuation of apoptosis underlies B lymphocyte stimulator enhancement of humoral immune response. J Exp Med 2000; 192:953-64.

23 Gross JA, Dillon SR, Mudri S, Johnston J, Littau A, Roque R, et al. TACl-lg neutralizes molecules critical for $B$ cell development and autoimmune disease. Impaired B cell maturation in mice lacking BLyS. Immunity 2001;15:289-302

24 Wang H, Marsters SA, Baker T, Chan B, Lee WP, Fu L, et al. TACl-ligand interactions are required for $T$ cell activation and collagen-induced arthritis in mice. Nat Immunol $2001 ; 2: 632-7$

25 Mackay F, Woodcock SA, Lawton P, Ambrose C, Baetscher M, Schneider $P$, et al. Mice transgenic for BAFF develop lymphocytic disorders along with autoimmune manifestations. J Exp Med 1999; 190: 1697-710.

26 Khare SD, Sarosi I, Xia XZ, McCabe S, Miner K, Solovyev I, et al. Severe B cell hyperplasia and autoimmune disease in TALL-1 transgenic mice. Proc Natl Acad Sci USA 2000;97:3370-5.

27 Schiemann B, Gommerman JL, Vora K, Cachero TG, Shulga-Morskaya $S$, Dobles $M$, et al. An essential role for BAFF in the normal development of $B$ cells through a BCMA-independent pathway. Science 2001.293.2111-14

28 Rolink A, Kudo A, Karasuyama H, Kikuchi Y, Melchers F. Long-term proliferating early pre $B$ cell lines and clones with the potential to develop to surface-lg positive mitogen-reactive $B$ cells in vitro and in vivo. EMBO J 1991;10:327-36

29 Fagarasan S, Kinoshita K, Muramatsu M, Ikuta K, Honjo T. In situ class switching and differentiation to lgA-producing cells in the gut lamina propria. Nature 2001;413:639-43.

30 Xu S, Lam KP. B-cell maturation protein, which binds the tumor necrosis factor family members BAFF and APRIL, is dispensable for humoral immune responses. Mol Cell Biol 2001:21:4067-74.

31 Yan M, Marsters SA, Grewal IS, Wang H, Ashkenazi A, Dixit VM Identification of a receptor for BLyS demonstrates a crucial role in humoral immunity. Nat Immunol 2000;1:37-41.

32 Hua X, Wu J, Goldstein JL, Brown MS, Hobbs HH. Structure of the human gene encoding sterol regulatory element binding protein-1 (SREBF1) and localization of SREBF 1 and SREBF2 to chromosomes 17 pl1.2 and 22q13. Genomics 1995;25:667-73.

33 Batten M, Groom J, Cachero TG, Qian F, Schneider P, Tschopp J, et al. BAFF mediates survival of peripheral immature B lymphocytes. J Exp Med 2000;192:1453-66.

34 Miller DJ, Hayes CE. Phenotypic and genetic characterization of a unique B lymphocyte deficiency in strain A/WySnJ mice. Eur J Immunol 1991;21:1123-30.

35 Miller DJ, Hanson KD, Carman JA, Hayes CE. A single autosomal gene defect severely limits $\lg G$ but not lgM responses in B lymphocyte-deficien A/WySnJ mice. Eur J Immunol 1992;22:373-9.

36 Lentz VM, Cancro MP, Nashold FE, Hayes CE. Bcmd governs recruitment of new $B$ cells into the stable peripheral $B$ cell pool in the A/WySnJ mouse. J Immunol 1996; 157:598-606

37 Rolink AG, Tschopp J, Schneider P, Melchers F. BAFF is a survival and maturation factor for mouse B cells. Eur J Immunol 2002;32:2004-10. 